\title{
Effectiveness of adenotonsillectomy in children with mild symptoms of throat infections or adenotonsillar hypertrophy: open, randomised controlled trial
}

\author{
Birgit K van Staaij, Emma H van den Akker, Maroeska M Rovers, Gerrit Jan Hordijk, Arno W Hoes, Anne G M \\ Schilder
}

\begin{abstract}
Objective To assess the effectiveness of adenotonsillectomy in children with mild symptoms of throat infections or adenotonsillar hypertrophy.

Design Open, randomised controlled trial.

Setting 21 general hospitals and three academic centres in the Netherlands.

Participants 300 children aged 2-8 years requiring adenotonsillectomy.

Intervention Adenotonsillectomy compared with watchful waiting.

Main outcome measures Episodes of fever, throat infections, upper respiratory tract infections, and health related quality of life.

Results During the median follow up period of 22 months, children in the adenotonsillectomy group had 2.97 episodes of fever per person year compared with 3.18 in the watchful waiting group (difference $-0.21,95 \%$ confidence interval -0.54 to 0.12$), 0.56$ throat infections per person year compared with $0.77(-0.21,-0.36$ to -0.06$)$, and 5.47 upper respiratory tract infections per person year compared with 6.00 $(-0.53,-0.97$ to -0.08$)$. No clinically relevant differences were found for health related quality of life. Adenotonsillectomy was more effective in children with a history of three to six throat infections than in those with none to two. 12 children had complications related to surgery.

Conclusion Adenotonsillectomy has no major clinical benefits over watchful waiting in children with mild symptoms of throat infections or adenotonsillar hypertrophy.
\end{abstract}

\section{Introduction}

Tonsillectomy, with or without adenoidectomy, is a common procedure in children in western countries, yet the indications for surgery remain uncertain, as reflected by the large variation in surgical rates across countries. In 1998, for example, 115 per 10000 children underwent adenotonsillectomy in the Netherlands, 65 per 10000 in England, and 50 per 10000 in the United States. ${ }^{1}$

We previously reported that in the Netherlands $35 \%$ of children underwent adenotonsillectomy for frequent throat infections (seven or more a year) or obstructive sleep apnoea, and the remainder for less frequent throat infections, mild adenotonsillar hypertrophy, or indications such as upper respiratory tract infections. ${ }^{2}$ Although frequent throat infections and obstructive sleep apnoea are considered adequate indications for adenotonsillectomy in children, ${ }^{3-8}$ evidence for the benefits of surgery in children with milder symptoms is lacking. ${ }^{29-12}$ We carried out a randomised controlled trial to assess the effectiveness of adenotonsillectomy in children with mild symptoms of throat infections or adenotonsillar hypertrophy.

\section{Participants and methods}

We carried out an open, multicentre, randomised controlled trial between March 2000 and February 2003. Otorhinolaryngologists from 21 general hospitals and three academic centres in the Netherlands were asked to complete a questionnaire on all their patients aged 2 to 8 years with indications for adenotonsillectomy according to current medical practice. They were asked to give the indication they considered most important for surgery: recurrent throat infections (three or more a year) or other indications such as obstructive problems or recurrent upper respiratory tract infections.

We excluded children with a history of seven or more throat infections in the preceding year, with five or more in each of the previous two years, or with three or more in each of the previous three years (Paradise criteria), ${ }^{3}$ and children with suspected obstructive sleep apnoea-that is, Brouillette's obstructive sleep apnoea score of more than 3.5. ${ }^{13}$ Other exclusion criteria were Down's syndrome, craniofacial malformations such as cleft palate, and immunodeficiency, other than deficiencies of IgA or $\operatorname{IgG}_{2}$.

\section{Randomisation}

Children whose parents gave informed consent were randomly assigned to either adenotonsillectomy within six weeks or watchful waiting. Randomisation was by a computer generated list of four numbers in each block and fixed blocks within each hospital.

When children were entered in the study, the study doctors completed a disease specific questionnaire on the basis of information provided by the parents. This elicited information on the number of throat infections and upper respiratory tract infections experienced by the children in the previous year; obstructive symptoms during sleep ${ }^{13}$; eating patterns; previous ear, nose, and throat operations; and risk factors for upper respiratory tract infections.

The participating hospitals and members of the executive steering committee are on bmj.com 




Fig 1 Flow of participants through trial

The parents completed two generic health related quality of life instruments: the TNO-AZL preschool children quality of life questionnaire (TAPQoL for children aged 2 to 5 years and TACQoL for children aged 5 years or older) and the child health questionnaire parental form (CHQpf50). ${ }^{14}{ }^{15}$ The children underwent an ear, nose, and throat examination and had their height and weight measured.

\section{Follow up}

The parents kept a diary of upper respiratory tract infections in their child, which included sore throat, pain or difficulty in swallowing, cough, rhinorrhoea, earache, and otorrhoea. They also noted absences from day care or school due to upper respiratory tract infections, and they measured the child's temperature daily with a validated tympanic membrane thermometer. ${ }^{16}$ To avoid information bias, we had an electronic device built into the thermometer, which stored the date and first measurement of each day. The study doctors collected the diary and thermometer data during follow up visits at 3, 6, 12, 18, and 24 months. At these visits, the disease specific and health related quality of life questionnaires were again completed. An ear, nose, and throat examination was carried out, and the child's height and weight were measured. The parents, general practitioners, and otorhinolaryngologists were encouraged to manage sore throats and upper respiratory tract infections during follow up according to regular practice.

\section{Primary and secondary outcomes}

Our primary outcome was the incidence of fever (a temperature of $38.0^{\circ} \mathrm{C}$ or higher) for at least one day, measured in number of episodes and days. An episode was considered finished when at least one day was without fever. New episodes were those occurring after a fever-free interval of at least seven days.

Secondary outcomes were throat infections, sore throat, upper respiratory tract infections, absence from day care or school due to upper respiratory tract infections, health related quality of life, patterns of sleep and eating, height, and weight. A throat infection was defined as sore throat or pain or difficulty in swallowing combined with fever. A sore throat was defined as sore throat or pain or difficulty in swallowing with or without fever. Upper respiratory tract infections were defined as one or more symptoms of sore throat, pain or difficulty in swallowing, cough, rhinorrhoea, earache, and otorrhoea with or without fever. Throat infections, sore throats, and upper respiratory tract infections were measured in episodes and days. We also included sore throats and upper respiratory tract infections immediately after adenotonsillectomy.

We calculated absence from day care or school due to upper respiratory tract infections on the basis of data from the diaries. We used the generic questionnaires to assess health related quality of life. ${ }^{14}$ Sleeping patterns were evaluated by Brouillette's obstructive sleep apnoea score and by the percentage of children experiencing snoring, difficulties breathing at night, or apnoea. ${ }^{13}$ Eating patterns were assessed by difficulties in eating solids.

\section{Statistical analysis}

Our sample size calculation was based on a clinically relevant reduction of fever episodes and throat infections after adenotonsillectomy of $25 \%$. Assuming a mean baseline (standard deviation) incidence of 4 (2) fever episodes and throat infections each year, and taking $\alpha=0.05$ and a power of 0.80 , we determined that we would need 104 children in each group. To allow for subgroup analyses, we aimed at including 300 children.

We calculated the effects of adenotonsillectomy on fever, sore throat, and upper respiratory tract infections as differences in incidence and incidence rate ratios per person year, with 95\% confidence intervals. Scores on health related quality of life instruments were linearly transformed into scales of 0-100. For the mean number of fever episodes we calculated a short term (0-6 months) and long term (6-24 months) effect. We also evaluated health related quality of life, sleep and eating patterns, height, weight, and short and long term effects at six and 24 months. We used $\chi^{2}$ tests and Student's $t$ tests to evaluate differences in percentages and mean values between the groups. We used the Bonferroni correction to adjust for multiple testing and the Mantel-Haenzel test to adjust for potential confounders. 
Table 1 Personal and clinical characteristics of 300 participants at baseline according to treatment allocation. Values are numbers (percentages) unless stated otherwise

\begin{tabular}{|c|c|c|}
\hline Characteristics & $\begin{array}{l}\text { Adenotonsillectomy group } \\
\qquad(\mathrm{n}=151)\end{array}$ & $\begin{array}{l}\text { Watchful waiting group } \\
\qquad(\mathrm{n}=149)\end{array}$ \\
\hline Boys & $81(54)$ & $66(44)$ \\
\hline Mean (SD) age (months) & $54(17.0)$ & $54(16.2)$ \\
\hline \multicolumn{3}{|l|}{ Indication for surgery: } \\
\hline Recurrent throat infections & $76(50.3)$ & $67(45.0)$ \\
\hline Other & $73(48.3)$ & $82(55.0)$ \\
\hline $\begin{array}{l}\text { Median No (range) of throat } \\
\text { infections in previous } \\
\text { year* }\end{array}$ & $3(0$ to 6$)$ & $3(0$ to 6$)$ \\
\hline $\begin{array}{l}\text { Median duration (months) of } \\
\text { throat infections (range) }^{*}\end{array}$ & 13 (0 to 50$)$ & 12 (0 to 60$)$ \\
\hline $\begin{array}{l}\text { Median No (range) of } \\
\text { episodes with rhinorrhoea } \\
\text { or cough in previous year }\end{array}$ & 12 (0 to 24$)$ & 10 (0 to 24$)$ \\
\hline $\begin{array}{l}\text { Median No (range) of } \\
\text { episodes of otitis media in } \\
\text { previous year }\end{array}$ & 0 (0 to 12) & 0 (1to 6) \\
\hline $\begin{array}{r}\text { Median obstructive sleep } \\
\text { apnoea score (range) } \dagger \\
\end{array}$ & -1.7 (-3.83 to 2.55$)$ & -1.7 (-3.83 to 2.56) \\
\hline \multicolumn{3}{|c|}{ Previous ear, nose, and throat surgery: } \\
\hline Adenoidectomy & $35(23.2)$ & $33(22.1)$ \\
\hline Tympanostomy tubes & $19(12.7)$ & $17(11.4)$ \\
\hline \multicolumn{3}{|l|}{ Enlarged tonsilsł: } \\
\hline Yes & $114(78.1)$ & $114(77.6)$ \\
\hline No & $32(21.9)$ & $33(22.4)$ \\
\hline Mean (SD) weight $(\mathrm{kg})$ & $18.6(4.0)$ & $19.0(4.4)$ \\
\hline Mean (SD) height $(\mathrm{cm})$ & $108(10.8)$ & $109(9.9)$ \\
\hline Atopy§ & $78(51.7)$ & $70(47.0)$ \\
\hline Breastfed for $>1$ month & $85(57.4)$ & $92(61.7)$ \\
\hline $\begin{array}{l}\text { Exposure to tobacco smoke } \\
\text { at home }\end{array}$ & $48(32.0)$ & $52(35.1)$ \\
\hline Day care attendanceף: & 49 (89.1) & 49 (89.1) \\
\hline \multicolumn{3}{|l|}{ No of siblings: } \\
\hline 0 & $32(21.2)$ & $27(18.1)$ \\
\hline 1 & $71(47.0)$ & $77(51.7)$ \\
\hline$\geq 2$ & $48(31.8)$ & $45(30.2)$ \\
\hline \multicolumn{3}{|l|}{ Father's level of education: } \\
\hline Low & $34(22.5)$ & $32(22.5)$ \\
\hline Average & $73(48.3)$ & $71(50.0)$ \\
\hline High & $44(29.1)$ & $39(27.5)$ \\
\hline \multicolumn{3}{|l|}{ Mother's level of education: } \\
\hline Low & $22(14.8)$ & $27(18.6)$ \\
\hline Average & $95(63.8)$ & $81(55.9)$ \\
\hline High & $32(21.5)$ & $37(25.5)$ \\
\hline
\end{tabular}

${ }^{*}$ Children with recurrent throat infections $(n=143)$.

tBrouilette's obstructive sleep apnoea score: $\leq 1$ (none), -1.0 to 3.5 (possible), >3.5 (highly predictive)

fProtruding beyond pillars but not meeting uvula, or meeting uvula

§History of eczema, hay fever, recurrent wheeze, or asthma.

IAged $<4$ years $(n=110)$.

As the estimates of effect were not influenced by these adjustments, we present the estimates of crude effect.

To detect possible modification from effects, we carried out subgroup analyses according to the burden of upper respiratory tract symptoms in the year before entry to the trial and age. We analysed interactions with Poisson regression. All analyses were performed on an intention to treat basis.

\section{Results}

Between March 2000 and August 2002 we enrolled 300 children in our study; 151 were allocated to adenotonsillectomy and 149 to watchful waiting (fig 1). Characteristics at baseline were similar between the two groups (table 1). Overall, 43 children (18 from the adenotonsillectomy group) were lost to follow up. Reasons
Table 2 Incidence of fever, throat infections, sore throats, and upper respiratory tract infections per person year for children with mild symptoms of throat infections or adenotonsillar hypertrophy after adenotonsillectomy or watchful waiting

\begin{tabular}{|c|c|c|c|c|}
\hline Variable & $\begin{array}{l}\text { Adenotonsillectomy } \\
\text { group }\end{array}$ & $\begin{array}{l}\text { Watchful } \\
\text { waiting } \\
\text { group }\end{array}$ & $\begin{array}{l}\text { Incidence rate } \\
\text { ratio }(95 \% \mathrm{CI})\end{array}$ & $\begin{array}{l}\text { Difference }(95 \% \\
\text { CI) }\end{array}$ \\
\hline \multicolumn{5}{|l|}{ Fever: } \\
\hline $\begin{array}{l}\text { No of } \\
\text { episodes }\end{array}$ & 2.97 & 3.18 & 0.94 (0.84 to 1.04) & $\begin{array}{c}-0.21 \\
(-0.54 \text { to } 0.12)\end{array}$ \\
\hline No of days & 5.31 & 5.93 & 0.90 (0.83 to 0.97$)$ & $\begin{array}{c}-0.62 \\
(-1.06 \text { to }-0.18)\end{array}$ \\
\hline \multicolumn{5}{|l|}{$\begin{array}{l}\text { Throat } \\
\text { infections: }\end{array}$} \\
\hline $\begin{array}{l}\text { No of } \\
\text { episodes }\end{array}$ & 0.56 & 0.77 & 0.73 (0.58 to 0.92$)$ & $\begin{array}{c}-0.21 \\
(-0.36 \text { to }-0.06)\end{array}$ \\
\hline No of days & 0.83 & 1.36 & $0.61 \quad(0.51$ to 0.73$)$ & $\begin{array}{c}-0.53 \\
(-0.73 \text { to }-0.34)\end{array}$ \\
\hline \multicolumn{5}{|l|}{ Sore throat: } \\
\hline $\begin{array}{l}\text { No of } \\
\text { episodes }\end{array}$ & 2.25 & 2.85 & 0.79 (0.70 to 0.89 ) & $\begin{array}{c}-0.60 \\
(-0.90 \text { to }-0.30)\end{array}$ \\
\hline No of days & 9.81 & 15.71 & 0.62 (0.59 to 0.66$)$ & $\begin{array}{c}-5.91 \\
(-6.57 \text { to }-5.24)\end{array}$ \\
\hline \multicolumn{5}{|l|}{$\begin{array}{l}\text { Upper } \\
\text { respiratory } \\
\text { tract } \\
\text { infections } \\
\text { and fever: }\end{array}$} \\
\hline $\begin{array}{l}\text { No of } \\
\text { episodes }\end{array}$ & 1.59 & 1.88 & 0.85 (0.73 to 0.98$)$ & $\begin{array}{c}-0.29 \\
(-0.53 \text { to }-0.04)\end{array}$ \\
\hline No of days & 2.81 & 3.63 & 0.77 (0.70 to 0.86$)$ & $\begin{array}{c}-0.82 \\
(-1.16 \text { to }-0.49)\end{array}$ \\
\hline \multicolumn{5}{|l|}{$\begin{array}{l}\text { Upper } \\
\text { respiratory } \\
\text { tract } \\
\text { infections: }\end{array}$} \\
\hline $\begin{array}{l}\text { No of } \\
\text { episodes }\end{array}$ & 5.47 & 6.00 & 0.91 (0.84 to 0.99$)$ & $\begin{array}{c}-0.53 \\
(-0.97 \text { to }-0.08)\end{array}$ \\
\hline No of days & 78.16 & 89.92 & 0.87 (0.85 to 0.89$)$ & $\begin{array}{c}-11.76 \\
(-13.47 \text { to }-10.05)\end{array}$ \\
\hline
\end{tabular}

were non-medical $(n=36)$, serious comorbidity $(n=1)$, or unknown $(n=6)$. Fifty children allocated to watchful waiting underwent adenotonsillectomy and seven allocated to adenotonsillectomy did not undergo surgery. Median follow up was 22.0 months in the adenotonsillectomy group and 22.4 months in the watchful waiting group.

\section{Outcomes}

Children in the adenotonsillectomy group had 0.21 fewer episodes of fever $(95 \%$ confidence interval -0.12 to 0.54 ) per person year (table 2). During the first six months of follow up, the number of episodes was lower in children in the adenotonsillectomy group. From six to 24 months there was no difference between the groups.

Compared with the watchful waiting group, children in the adenotonsillectomy group had, per person year, fewer throat infections $(0.21,95 \%$ confidence interval 0.06 to 0.36$)$, fewer sore throats $(0.60,0.30$ to 0.90$)$, fewer days with sore throat $(5.91,5.24$ to 6.57$)$, and fewer upper respiratory tract infections $(0.53,0.08$ to 0.97 ; see table 2 ).

Absence from day care or school due to upper tract respiratory infections was comparable between the groups (difference $0.09,-0.27$ to 0.44$)$.

At six months, small significant differences were found for some domains of the health related quality of life questionnaires, but these were not clinically relevant. We found no differences in other domains and at 24 months (figs 2 and 3).

At six months, Brouillette's scores were lower for children in the adenotonsillectomy group (fig 4). At 24 months there was no 


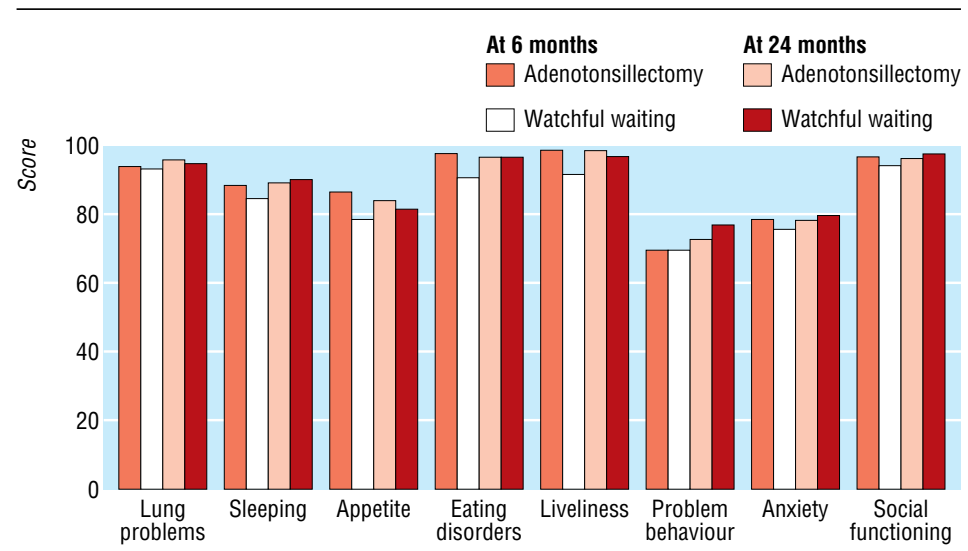

Fig 2 Health related quality of life (preschool children quality of life questionnaire; TAPQoL) six and 24 months after adenotonsillectomy or watchful waiting for children aged 2-5 years

difference between the groups. Fewer children in the adenotonsillectomy group experienced snoring and difficulties in eating at six months, whereas there were no differences at 24 months (data not shown). Height and weight of children in both groups remained similar during follow up (data not shown).

\section{Subgroup analysis}

The effects of adenotonsillectomy were more pronounced in children who had had three to six throat infections in the year before entry to the trial than in those with none to two throat infections: fever episodes (difference - 1.07 (95\% confidence

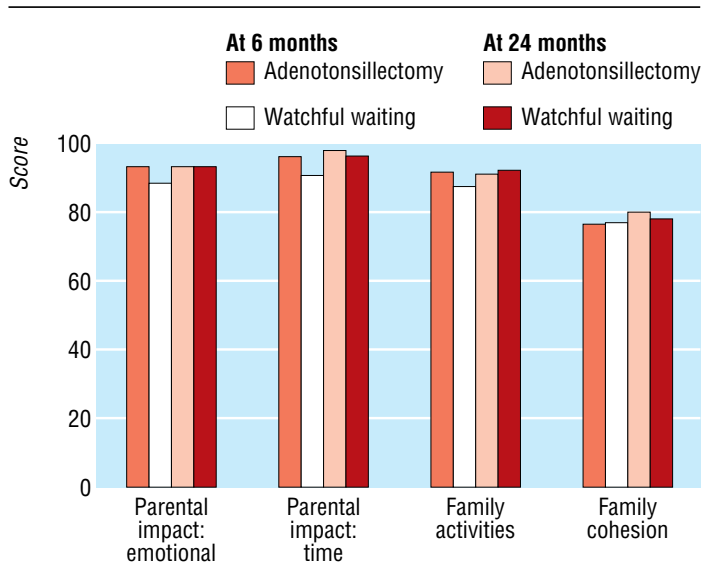

Fig 3 Health related quality of life (child health questionnaire parental form) six and 24 months after adenotonsillectomy or watchful waiting

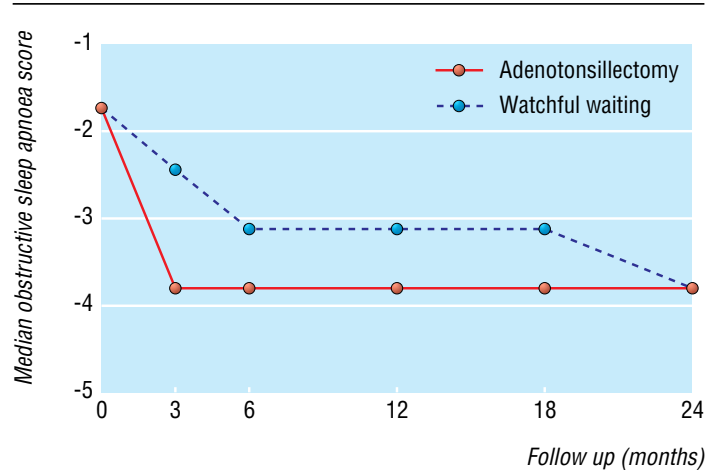

Fig 4 Median Brouillette's obstructive sleep apnoea scores for children after adenotonsillectomy or watchful waiting interval -1.59 to -0.56$) v 0.34(-0.08$ to 0.77$), \mathrm{P}=0.01$; table 3$)$ and days with sore throat per person year (difference -11.33 $(-12.48$ to -10.17$) v-2.38(-3.19$ to -1.60$), \mathrm{P}=0.01)$. Age did not influence the effectiveness of adenotonsillectomy.

\section{Complications of surgery}

Of the 195 children who underwent adenotonsillectomy (145 in the adenotonsillectomy group and 50 in the watchful waiting group), 12 (6\%) had complications related to surgery. Seven children $(4 \%)$ had primary haemorrhage: two $(1 \%)$ were managed surgically, five $(3 \%)$ were managed non-surgically; and three $(2 \%)$ were admitted for overnight observation. None of these children needed a blood transfusion. Five children (3\%) had postoperative nausea, which was managed by antiemetics and intravenous hydration.

\section{Discussion}

Adenotonsillectomy for mild symptoms of throat infections or adenotonsillar hypertrophy in children has little clinical benefit over watchful waiting. Surgery marginally reduced the number of episodes of fever, throat infections, and upper respiratory tract infections per person year. The effects of surgery were more pronounced in children who had had three to six throat infections in the year before entry to the trial than in those with none to two throat infections. No clinically relevant differences were found for health related quality of life.

\section{Short term effect}

During the first six months of follow up the incidence of fever was significantly lower in the adenotonsillectomy group than in the watchful waiting group, but was the same from six to 24 months. Sleep and eating patterns initially improved more in children in the adenotonsillectomy group, but by 24 months the differences had disappeared. The reduction of problems in the first six months might explain why parents and doctors are usually satisfied with adenotonsillectomy. ${ }^{17} 18$

\section{Possible limitations}

Our trial has several limitations. Firstly, we excluded children with frequent throat infections or obstructive sleep apnoea, which are generally considered adequate indications for surgery. Our results are therefore generalisable only to children with milder symptoms of throat infections or adenotonsillar hypertrophy.

Secondly, 50 children (34\%) changed from watchful waiting to surgery. Similar rates have been reported. ${ }^{39-22}$ In surgical tri- 
Table 3 Differences in incidence of fever, throat infections, upper respiratory tract infections, and days with sore throat in subgroups of children after adenotonsillectomy or watchful waiting for mild symptoms of throat infections or adenotonsillar hypertrophy

\begin{tabular}{|c|c|c|c|c|c|c|c|c|}
\hline Variable & Fever $(95 \% \mathrm{CI})$ & $P$ value* & $\begin{array}{l}\text { Throat infections }(95 \% \\
\text { Cl) }\end{array}$ & $P$ value ${ }^{*}$ & $\begin{array}{l}\text { Days with sore throat } \\
(95 \% \mathrm{CI})\end{array}$ & $P$ value ${ }^{*}$ & $\begin{array}{l}\text { Upper respiratory tract } \\
\text { infections }(95 \% \mathrm{Cl})\end{array}$ & $P$ value \\
\hline Overall & $-0.21(-0.54$ to 0.12$)$ & & $-0.21(-0.36$ to -0.06$)$ & & $-5.91(-657$ to -5.24$)$ & & $-0.53(-0.97$ to -0.08$)$ & \\
\hline \multicolumn{9}{|l|}{ Indication: } \\
\hline $\begin{array}{l}\text { Recurrent throat } \\
\text { infections }\end{array}$ & $-0.84(-1.33$ to -0.35$)$ & \multirow[t]{2}{*}{0.10} & $-0.38(-0.62$ to -0.13$)$ & \multirow[t]{2}{*}{0.12} & $-9.70(-10.79$ to -8.61$)$ & \multirow[t]{2}{*}{0.06} & $-0.33(-0.99$ to 0.34$)$ & \multirow[t]{2}{*}{0.79} \\
\hline Other & $0.27(-0.18$ to 0.72$)$ & & $-0.08(-0.28$ to 0.11$)$ & & $-3.19(-4.04$ to -2.35$)$ & & $-0.63(-1.24$ to -0.02$)$ & \\
\hline \multicolumn{9}{|c|}{ No of throat infectionst: } \\
\hline $0-2$ & 0.34 (-0.08 to 0.77$)$ & \multirow[t]{2}{*}{0.01} & $-0.03(-0.21$ to 0.15$)$ & \multirow[t]{2}{*}{0.05} & $-2.38(-3.19$ to -1.60$)$ & \multirow[t]{2}{*}{0.01} & $-0.27 \quad(-0.86$ to 0.32$)$ & \multirow[t]{2}{*}{0.18} \\
\hline $3-6$ & $-1.07(-1.59$ to -0.56$)$ & & $-0.49(-0.75$ to -0.22$)$ & & $-11.33(-12.48$ to -10.17$)$ & & $-0.92(-1.61$ to -0.23$)$ & \\
\hline
\end{tabular}

*Values of interaction term in Poisson regression analysis.

†ln year before entry to trial.

als, only the children in the watchful waiting group are allowed to change treatment group because of persisting problems. Per protocol analyses that exclude children who change groups will therefore underestimate the effect of treatment. Conversely, analysing children on the basis of time spent in a treatment arm might overestimate or underestimate this effect. For these reasons we chose an intention to treat analysis.

Thirdly, we measured health related quality of life with generic questionnaires because disease specific instruments for children with tonsil and adenoid disease were not available when we started our study. ${ }^{23}$ We chose the TAPQoL and TACQoL preschool children quality of life questionnaires because they include domains relevant for children with tonsil and adenoid disease. ${ }^{14}$ We did not expect large improvements during follow up, because the scores of our study population at baseline were similar to those of healthy children.

Finally, not all eligible children entered the trial, which might have influenced the generalisability of our results. In an earlier study, however, we found no major differences between included children and those who were eligible but not included. ${ }^{24}$

\section{Strengths of the study}

Previous trials are potentially limited by information bias. This is due to the absence of an objective outcome measure and because the parents of children in the watchful waiting group are more likely to report sore throat or upper respiratory tract infections than parents of children in the intervention group. ${ }^{319-22} 25$ These lead to an overestimation of the intervention effect. ${ }^{26}{ }^{27}$ The major strength of our study is the inclusion of the objective primary outcome of fever measured daily by a validated thermometer that automatically stored data. ${ }^{16}$ Fever is an important physical sign in many diseases of children, and most episodes of fever in children under 8 years of age are caused by upper respiratory tract infections. ${ }^{28}{ }^{29}$ We found that adenotonsillectomy did not significantly reduce the number of fever episodes but did have a small but statistically significant effect on the number of throat infections.

The power of our study was large enough to allow for subgroup analyses, providing a tool for clinicians to identify children who are likely to benefit from adenotonsillectomy.

We thank the participants and their parents; our colleagues and nurses in the participating hospitals; Nelly van Eden for secretarial support; Patrick Poels, Ward Videler, Charlotte van Krevel, and Wytske Richard for help with the conduct of the trial and recruitment of the patients; and Frank Leus for data management.

Contributors: BKvS and EhvdA planned the study; collected, analysed, and interpreted the data; and wrote the paper equally. MMR analysed and interpreted the data. GJH contributed to the initial concept and design of the study and interpreted the data. AGMS and AWH designed, planned, and supervised the study and interpreted the data. The manuscript was

\section{What is already known on this topic}

Frequent throat infections and obstructive sleep apnoea are adequate indications for adenotonsillectomy

Evidence of the benefits of adenotonsillectomy in children with milder symptoms is lacking

\section{What this study adds}

Adenotonsillectomy has no major clinical benefits over watchful waiting in children with mild symptoms of throat infections or adenotonsillar hypertrophy

prepared by BKvS and EHvdA and commented on by all authors. AGMS is guarantor.

Funding: Dutch Health Care Insurance Board (OG-99-060).

Competing interests: None declared.

Ethical approval: This study was approved by the medical ethics committees of all participating hospitals.

1 Van den Akker EH, Hoes AW, Burton MJ, Schilder AGM. Large international differences in (adeno)tonsillectomy rates. Clin Otolaryngol 2004:29:161-4.

2 Van den Akker EH, Schilder AG, Kemps YJ, van Balen FA, Hordijk GJ, Hoes AW. Current indications for (adeno)tonsillectomy in children: a survey in the Netherlands. Int J Pediatr Otorhinolaryngol 2003;67:603-7.

3 Paradise JL, Bluestone CD, Bachman RZ, Colborn DK, Bernard BS, Taylor FH, et al. Efficacy of tonsillectomy for recurrent throat infection in severely affected children. Results of parallel randomized and nonrandomized clinical trials. $N$ Engl J Med 1984;310:674-83.

4 Nieminen P, Tolonen U, Lopponen H. Snoring and obstructive sleep apnea in children: a 6-month follow-up study. Arch Otolaryngol Head Neck Surg 2000;126:481-6.

5 De Serres LM, Derkay C, Astley S, Deyo RA, Rosenfeld RM, Gates GA. Measuring quality of life in children with obstructive sleep disorders. Arch Otolaryngol Head Neck Surg 000;126:1423-9.

6 Flanary VA. Long-term effect of adenotonsillectomy on quality of life in pediatric patients. Laryngoscope 2003;113:1639-44

7 Scottish Intercollegiate Guidelines Network. 1999. www.sign.ac.uk/guidelines (accessed 20 May 2004).

8 American Academy of Otolaryngology-Head and Neck Surgery. 2000. Clinical indicators for otolaryngology-head and neck surgery. 2000. www.entlink.net/practice/ products/indicators/tonsillectomy.html (accessed 17 Jun 2004).

9 Blair RL, McKerrow WS, Carter NW, Fenton A. The Scottish tonsillectomy audit. Audit Sub-Committee of the Scottish Otolaryngological Society. I Laryngol Otol 1996;110(suppl 20):1-25.

10 Donnelly MJ, Quraishi MS, McShane DP. Indications for paediatric tonsillectomy: GP versus consultant perspective. J Laryngol Otol 1994;108:131-4

11 Capper R, Canter RJ. Is there agreement among general practitioners, paediatricians and otolaryngologists about the management of children with recurrent tonsillitis? Clin Otolaryngol 2001;26:371-8.

12 Faulconbridge RV, Fowler S, Horrocks J, Topham JH. Comparative audit of tonsillectomy. Clin Otolaryngol 2000;25:110-7.

13 Brouillette R, Hanson D, David R, Klemka L, Szatkowski A, Fernbach S, et al. A diagnostic approach to suspected obstructive sleep apnea in children. $J$ Pediatr 1984;105:10-4.

14 Fekkes M, Theunissen NC, Brugman E, Veen S, Verrips EG, Koopman HM, et al. Development and psychometric evaluation of the TAPQoL: a health-related quality of life instrument for 1-5-year-old children. Qual Life Res 2000;9:961-72.

15 Raat H, Bonsel GJ, Essink-Bot ML, Landgraf JM, Gemke RJ. Reliability and validity of comprehensive health status measures in children: the child health questionnaire in comprehensive health status measures in children: the child healt
relation to the health utilities index. J Clin Epidemiol 2002;55:67-76.

16 Van Staaij BK, Rovers MM, Schilder AG, Hoes AW. Accuracy and feasibility of daily infrared tympanic membrane temperature measurements in the identification of fever in children. Int J Pediatr Otorhinolaryngol 2003;67:1091-7. 
17 Wolfensberger M, Haury JA, Linder T. Parent satisfaction 1 year after adenotonsillectomy of their children. Int J Pediatr Otorhinolaryngol 2000;56:199-205

18 Conlon BJ, Donnelly MJ, McShane DP. Improvements in health and behaviour following childhood tonsillectomy: a parental perspective at 1 year. Int J Pediatr Otorhinolaryngol 1997;41:155-61.

19 McKee WJE. A controlled study of the effects of tonsillectomy and adenoidectomy in children. Br J Prev Soc Med 1963;17:49-69.

20 Mawson SR, Adlington P, Evans M. A controlled study evaluation of adenotonsillectomy in children.J Laryngol Otol 1967;81:777-90.

21 Mawson SR, Adlington P, Evans M. A controlled study evaluation of adenotonsillectomy in children. Part II. J Laryngol Otol 1968;82:963-79.

22 Paradise JL, Bluestone CD, Colborn DK, Bernard BS, Rockette HE, Kurs-Lasky M. Tonsillectomy and adenotonsillectomy for recurrent throat infection in moderately sillectomy and adenotonsillectomy for
affected children. Pediatrics 2003;110:7-15.

23 Stewart MG, Friedman EM, Sulek M, deJong A, Hulka GF, Bautista MH, et al. Validation of an outcomes instrument for tonsil and adenoid disease. Arch Otolaryngol Head Neck Surg 2001;127:29-35.

24 Van den Akker EH, Rovers MM, van Staaij BK, Hoes AW, Schilder AG. Representativeness of trial populations: an example from a trial of adenotonsillectomy in children. Acta Otolaryngol 2003;123:297-301.

25 McKee WJE. The part played by adenoidectomy in the combined operation of tonsillectomy with adenoidectomy. Second part of a controlled study in children. Br JPrev Soc Med 1963:17:133-40

26 Van der Graaf Y. Clinical trials: study design and analysis. Eur J Radiol 1998:27:108-15.

27 McLeod RS. Issues in surgical randomized controlled trials. World J Surg McLeod RS. $1999 \cdot 23 \cdot 1210-4$
28 Eskerud JR, Laerum E, Fagerthun H, Lunde PKM, Naess A. Fever in general practice. 1. Frequency and diagnoses. Fam Pract 1992;9:263-9.

29 Soman M. Characteristics and management of febrile young children seen in a university family practice.J Fam Pract 1985;21:117-22.

(Accepted 6 July 2004)

doi $10.1136 /$ bmj.38210.827917.7C

Julius Center for Health Sciences and Primary Care, University Medical Center Utrecht, PO Box 85060, 3508 AB Utrecht, Netherlands

Birgit K van Staaij general practitioner

Maroeska M Rovers clinical epidemiologist

Arno W Hoes professor

Department of Otorhinolaryngology, Wilhelmina Children's Hospital, University

Medical Center Utrecht, PO Box 85090, 3508 AB Utrecht, Netherlands

Emma $\mathrm{H}$ van den Akker otorhinolaryngologist

Anne G M Schilder otorhinolaryngologist

Department of Otorhinolaryngology, Head and Neck Surgery, University Medical Center Utrecht, 3584 CX Utrecht, Netherlands

Gerrit Jan Hordijk professor

Correspondence to: A G M Schilder A.Schilder@wkz.azu.nl 